\title{
Thermal Product of Fast Response Temperature Sensors for Transient Heat Transfer Applications with Numerically Determined Surface Heat Flux History
}

\author{
Hussein A. Mohammed*, Hanim Salleh and Mohd Zamri Yusoff \\ Department of Mechanical Engineering, College of Engineering, Universiti Tenaga Nasional, Km 7, Jalan Kajang- \\ Puchong, 43009 Kajang, Selangor, Malaysia
}

\begin{abstract}
A dynamic calibration technique for evaluating the thermal product values of different scratched temperature sensors is presented. These sensors have renewable junction, fast response time and it can be used for transient heat transfer measurements in hypersonic vehicles. Two types of scratch were used, mainly abrasive papers with different grit sizes and scalpel blades with different thicknesses to form the sensor junction. The effect of scratch technique on the sensor's thermal product is investigated. The sensors were tested in shock tube facility at different operating conditions. It was observed that the thermal product of a particular sensor depends on the Mach number, surface junction scratch technique, junction location as well as on the enthalpy conditions. It was also noticed that using scalpel blade technique with a particular blade size gives consistent thermal product values. Thus, it does not require an individual calibration. However, for sensors whose junction created using abrasive paper technique with different grit sizes, a calibration for each sensor is likely to be needed. The present results have provided useful and practical data for thermal product values for different scratched temperature sensors. These data are beneficial to the experimentalists in the field and it can be used for accurate transient heat transfer rate determination. Furthermore, the present calibration technique has shown that the response time of these sensors is on the order of microseconds (less than $50 \mu \mathrm{s}$ ) and it has a rise time less than $0.3 \mu \mathrm{s}$. A numerical technique was used in the calculation of the heat transfer rate by developing a MATLAB routine to obtain the transient heat flux history from the measured surface temperatures history.
\end{abstract}

Keywords: Thermal product, fast response temperature sensors, numerical algorithm, transient heat transfer applications.

\section{INTRODUCTION}

The accurate measurement of heat transfer rates has long been recognized as a key to improvements in unsteady energy conversion devices such as internal combustion engines [1-6] and aerodynamics vehicles [7-9], gun barrels [10] and in boiling experiments [11-13]. The heat flow in these devices is usually quite high (hundreds of kilowatts per square meter) and very unsteady. Thus, the requirement for a rugged and fast response temperature sensor is necessary for these applications. The coaxial temperature sensor was chosen in this work as it offers distinctive advantages: (i) it is easy to construct with low cost compared with the commercial one [14]; (ii) its sensing surface can be maintained from time to time if broken during the experiment; (iii) it has fast response time (less than $50 \mu \mathrm{s}$ ); (iv) it is stable and repeatable in dynamic calibration experiments; (v) it is easy to be contoured to any model surface (cone, cylinder, sphere, etc) due to its small size and sturdy design. The coaxial sensor design is originally proposed by Bendersky [15], which was made up of a small wire, consisting one thermoelement, which is coated with very thin of $12 \mu \mathrm{m}$ aluminum oxide insulation

*Address correspondence to this author at the Department of Mechanical Engineering, College of Engineering, Universiti Tenaga Nasional, $\mathrm{Km} \mathrm{7}$, Jalan Kajang-Puchong, 43009 Kajang, Selangor, Malaysia; Tel: +6 03-8921 2116; Fax: +6 03-8921 2265; Email: hussein@uniten.edu.my and securely inserted in a tube, consisting the second thermoelement. Other surface sensors have been fabricated using scratches from abrasive paper or a sharp implement [16]. The surface sensors have also been manufactured using two parallel wires [17] or ribbon elements [1-3] that are insulated from each other except at the exposed surface.

The coaxial temperature sensor provides a measurement of temperature close to the surface of interest because of the low thermal inertia of its junction. In order to identify the instantaneous heat flux history from the measured surface temperature history, it is necessary to apply a suitable experimental technique to acquire the accurate and single value of its thermal product $(\beta)$ for each particular sensor under the transient heat conduction process. All temperature sensors used in this work were constructed in our laboratory, its fabrication details is comprehensively reported in [18]. Furthermore, the calibration of each temperature sensor is essential as there will be errors up to $23 \%$ or even higher [18] if the thermophysical properties of the sensor materials are obtained from the literature [19-21]. Many investigators have measured the thermal product using different techniques. Alkidas and Cole [2] calibrated heat flux probes using a water-cooled, high intensity radiation source with $36 \mathrm{~kW}$, and with a reference heat flux sensor. A radiative technique with laser pulse technique was used by Gatowski et al. [4] to measure the value of $(\beta)$ and to identify the response time for 
several types of surface temperature probes. However, this technique requires a lump of calibrated intensity, a value for the absorbtivity of the assembled probe surface, and a relatively long exposure time (on the order of 100 millisecond) to achieve useful surface temperature changes. The same technique was employed by Buttsworth et al. [22] using tungsten-halogen lamp to provide a step heat flux input to eroding ribbon commercial probe type-K [14] for relatively long time scales, from about 0.1 to $1 \mathrm{~s}$. This may lead to an inappropriate value of $(\beta)$ if the time scales of interest are much shorter than can be assessed with this calibration technique. Kovács and Mesler [15] utilized a $200 \mathrm{~J}$ flash tube as a high intensity transient heat source to observe the response of a surface probe as a function of the size and the type of junction. However, it is difficult to determine the appropriate $(\beta)$ at short time scales (around $50 \mu \mathrm{s}$ ) using this technique. This is because this technique leads to erroneous values of $(\beta)$ due to two main factors: (i) the absorbtivity of the probe surface cannot be accurately predicted. The absorbtivity uncertainties cannot be overcome for short time scale calibrations through the application of carbon black to the surface because this additional layer thickness will alter the temporal response of the probe. Furthermore, (ii) the exposure time is much longer than the intended application of the probes. The laser pulse technique was proposed by Heichal et al. [23] to assess the dynamic performance of a surface probe by measuring its Unit-Impulse Response-Function (UIRF). Sprinks [24] presented a numerical technique to determine the thermal capacitance of calorimeter gauge using plunging technique. However, this technique is not preferable as it needs knowledge of the thermophysical properties of the fluid, and measurements of both the initial bath temperature and the gauge temperature during the plunging process. Furthermore, this technique is only suitable for identifying the thermal product values for millisecond time scales. Lyons and Gai [25] described a method for determining the thermal product $(\beta)$ for thin film or surface probe at a given temperature rise using an optical technique with a known laser power. Although, this technique was shown to be quick, versatile and can be used to calibrate either thin film or surface probe with equal ease. However, this method is costly and it requires special equipment, thus it is undesirable.

In summary, although prior works have investigated the insulation influence [16] but they did not clearly identify the importance of the various sensor materials including the thermophysical property difference between the positive and negative sensor elements. Furthermore, they did not also identify the thermal product values $(\beta)$ for different sensors with different sensing surfaces for microsecond time scales. Gai and Joe [8] calibrated surface probes in a free piston driven shock tunnel to measure the heat transfer rate on spherically blunted cone of various bluntness ratios. The same calibration technique was used by Sanderson and Sturtevant [9] to test surface probe to measure the stagnation point heat transfer rate experienced by a circular cylinder in hypervelocity flow. Although, they have calibrated their surface probes in a free piston shock tunnel but they did not identify the appropriate thermal product values. Thus, in this article an experimental verification of evaluating the thermal product values of miniature, reliable, fast response temperature sensors is presented. This paper also discusses the performance of these sensors in hypersonic facility to demon- strate their capability to withstand the high enthalpy conditions. The effect of using different scratch type, mainly abrasive paper and scalpel blade, on the sensors thermal product values is also investigated. The transient heat flux history was calculated from the measured surface temperatures history by developing a MATLAB routine. An example of the transient heat flux history produced from one of the fabricated temperature sensors is depicted and interpreted.

\section{SENSORS CONSTRUCTION}

\section{A) Fabrication Technique}

A short brief of the construction steps of the temperature sensor is given below (see for more details Ref. [18]). Generally temperature sensor comprises a centre post or rod composed of one of its materials which is coaxially set in and attached to the closed end of a tube composed of the second material. The current design and fabrication approach depends mainly on the thermoelectric emf produced at a junction of dissimilar metals. If these materials are deposited on an insulating substrate, then the sensitivity of the sensor is only function of the substrate and sensor material properties. This work uses the sensor material itself as the substrate to produce a particularly robust design and to tolerate a larger transient heat flux. The temperature sensor were designed and fabricated from type-K elements (alumel/chromel). They consist of $1 \mathrm{~mm}$ inner wire of one element positive or negative and a hollow machined annulus with $2 \mathrm{~mm}$ from the other element either positive or negative having a thickness of $0.25 \mathrm{~mm}$. The preparation of the inner wire and the outer annulus was done by using a wire cutting machine and the annulus was drilled using a drill bite with very fine thickness. The inner wire was then disposed symmetrically and coaxially into a hollow machined cylinder of the other element.

The method adopted to form the sensor junction was by abrasing its exposed surface to burr across the small gap. In this case very fine tolerances are required to produce a small gap between the sensor elements and the effective thickness of the junction scales with the width of the gap. Thus, the sensors junctions were formed by gently sanding its end surface using two different scratch techniques, (i) abrasive paper with different grit sizes; (ii) scalpel blade with different thicknesses. The abrasive papers have the following grit sizes 80\#, 150\#, 200\#, 320\#, 400\#, 600\#, 800\#, 1000\#, $1200 \#, 1500 \#$, and 2000\#. The scalpel blades have the following thicknesses $20 \mu \mathrm{m}, 40 \mu \mathrm{m}$, and $60 \mu \mathrm{m}$. In addition, the sensor two elements were insulated by a very thin layer of epoxy 'Araldite' having a few micrometers thickness. The schematic diagram of the final temperature sensor assembly is shown in Fig. (1).

The electrical lead connection of the assembly was carried out using a standard teflon wire (34 AWG) with an outer diameter of $0.8 \mathrm{~mm}$, which was welded, to serve as an extension wire to the reference junction, with the two probe elements. Then, application of an epoxy resin was deposited right after the welding process. The assembly was then placed inside a stainless steel cylinder with $0.1 \mathrm{~mm}$ thickness to isolate it, both thermally and electrically, from the brass bolt. The temperature sensors were carefully embedded in a mounting bush before they were calibrated to make inter- 
changing sensors relatively easy. Super glue was then applied to the sides of the sensor before they were inserted into the bush. A brass locking bolt with M6 external thread is used to secure the mounting bush into the wall of the shock tube. Another type of insulation was applied to fill in the gap between the inside surface of the brass bolt and the temperature sensor elements to ensure that the measurement was not affected by either materials dissimilarity or lateral heat conduction.

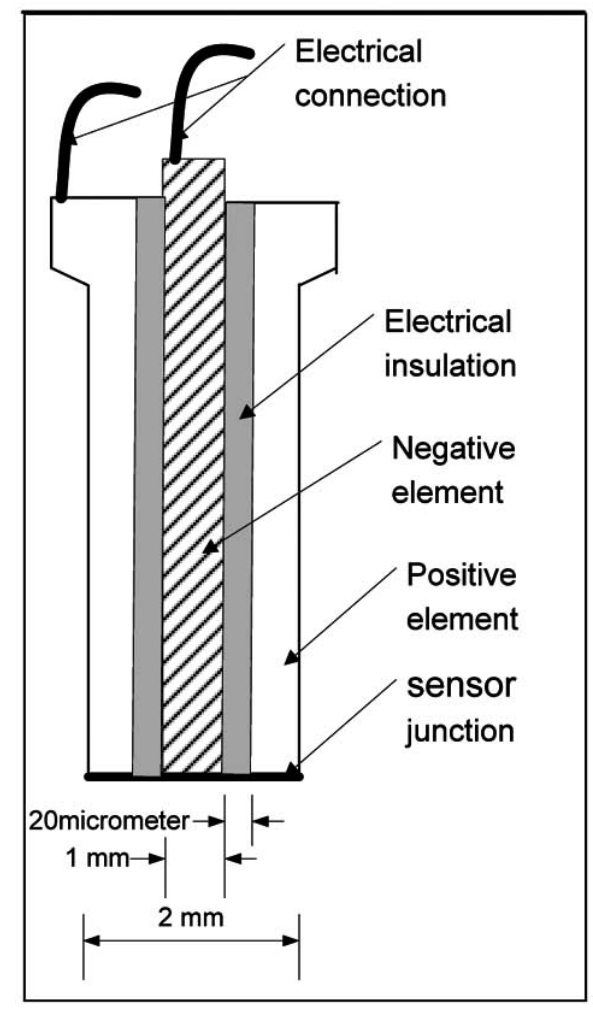

Fig. (1). The schematic diagram of temperature sensor assembly.

\section{B) Sensors Thermophysical Properties}

One of the objectives of this work is to accurately measure the time-varying surface heat flux using the fabricated temperature sensor. Thus, there is a need to know the thermophysical properties of the substrate or more precisely the value of the thermal product $(\beta)$. Therefore, new correlation equations to evaluate the thermophysical properties for temperature sensor elements are developed in order to have another way to determine the thermophysical properties consistently with a high level of accuracy.

The thermophysical properties selection of temperature sensor elements was taken from Caldwell [26] and Touloukian [27, 28]. However, according to Caldwell [26], the approximate analysis of temperature sensor type-K elements are: (i) the alumel constituents are: $94-96 \% \mathrm{Ni}, 1-1.5 \% \mathrm{Si}$, $1.3-2.5 \% \mathrm{Al}, 1.8-3.25 \% \mathrm{Mn}$, and iron and other constituents in smaller quantities; (ii) the chromel constituents are: 89$90 \% \mathrm{Ni}, 9-9.5 \% \mathrm{Cr}$, up to $0.5 \% \mathrm{Si}, 0.02-0.65 \% \mathrm{Fe}$, and 0.01 to $0.8 \% \mathrm{Mn}$. Although, the nickel is the major constituent of type-K elements, there are significant differences in the thermophysical properties of the chromel and alumel materials. Furthermore, according to Touloukian [27] the alumel consists of $72 \% \mathrm{Ni}, 25 \% \mathrm{Mn}, 2 \% \mathrm{Al}, 1 \% \mathrm{Si}$ and the chromel is the same as Caldwell's one (i.e., $90 \% \mathrm{Ni}, 10 \% \mathrm{Cr}$ ). As has been highlighted by the same authors [18] that the values of $(\beta)$ for both alumel and chromel elements differ from each other around $23 \%$ at $25{ }^{\circ} \mathrm{C}$ and it is also differed from the mean value by around $15 \%$ at ambient temperature. Conclusively, a dynamic calibration for each particular temperature sensor is required for accurate results. Therefore, the data were collated again from Caldwell [26] and Touloukian [27, 28]. New correlation equations were developed for the specific heat and thermal conductivity of both elements and presented as functions of temperature in Figs. (2 and $\mathbf{3}$ ).

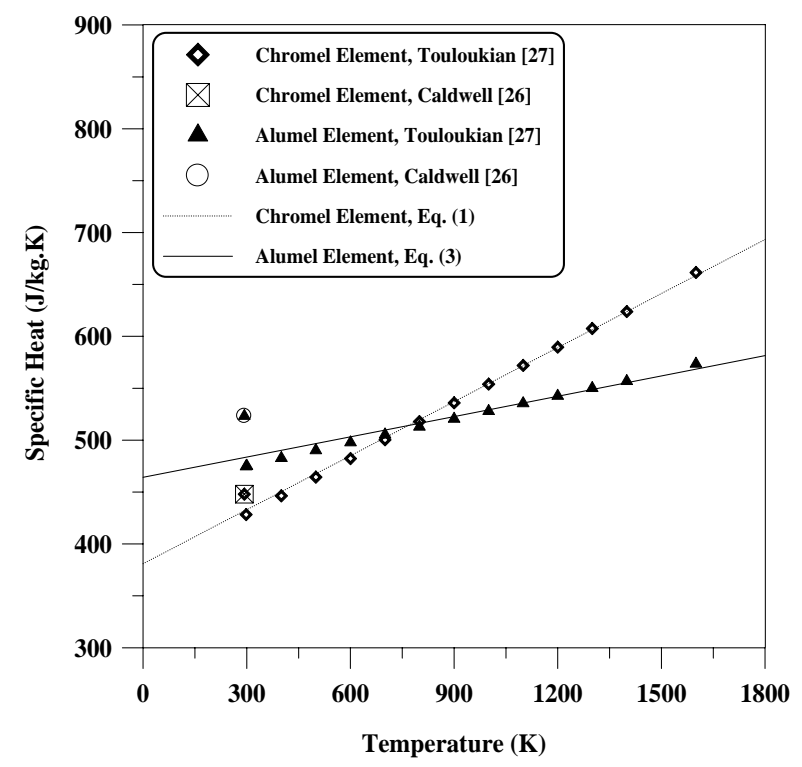

Fig. (2). The specific heat variation with the temperature for temperature sensor elements.

These straight-line correlations were typically obtained by identifying the slope from the data in Touloukian [27, 28] and the intercept from the data reported in Caldwell [26]. This approach is most obvious from the alumel specific heat correlation (Fig. 2) where the closest material composition reported in Touloukian [27] $(72 \% \mathrm{Ni}, 1 \% \mathrm{Si}, 2 \% \mathrm{Al}, 25 \%$ $\mathrm{Mn})$ differs significantly from the alumel analysis reported by Caldwell [26]. Thus, the following correlation equations are developed:

For chromel and alumel elements:

$\mathrm{c}_{\mathrm{cr}}=0.178664 \mathrm{~T}+375.053$

$\mathrm{K}_{\mathrm{cr}}=0.0191199 \mathrm{~T}+11.8513$

$\mathrm{c}_{\mathrm{al}}=0.0751194 \mathrm{~T}+452.678$

$\mathrm{K}_{\mathrm{al}}=0.0298301 \mathrm{~T}+17.9676$

In addition, the values of $\beta$ for both alumel and chromel elements, based on the developed correlation equations Eqs.1-4 and the reported densities, can easily be calculated as a function of temperature. At $20{ }^{\circ} \mathrm{C}, \beta_{\mathrm{cr}}=8070 \mathrm{~J} / \mathrm{m}^{2} . \mathrm{K} . \mathrm{s}^{1 / 2}$ and $\beta_{\mathrm{al}}=10442 \mathrm{~J} / \mathrm{m}^{2} . \mathrm{K} . \mathrm{s}^{1 / 2}$ which amounts to a difference of $2372 \mathrm{~J} / \mathrm{m}^{2} . \mathrm{K} . \mathrm{s}^{1 / 2}$ or around $23 \%$. Thus, a dynamic calibration 
for each temperature sensor is required as the effective value of the thermal product for a particular temperature sensor construction depends upon the junction location whether it is on the chromel or alumel elements and its vicinity to the electrical insulation as will be demonstrated in the results and discussion section.

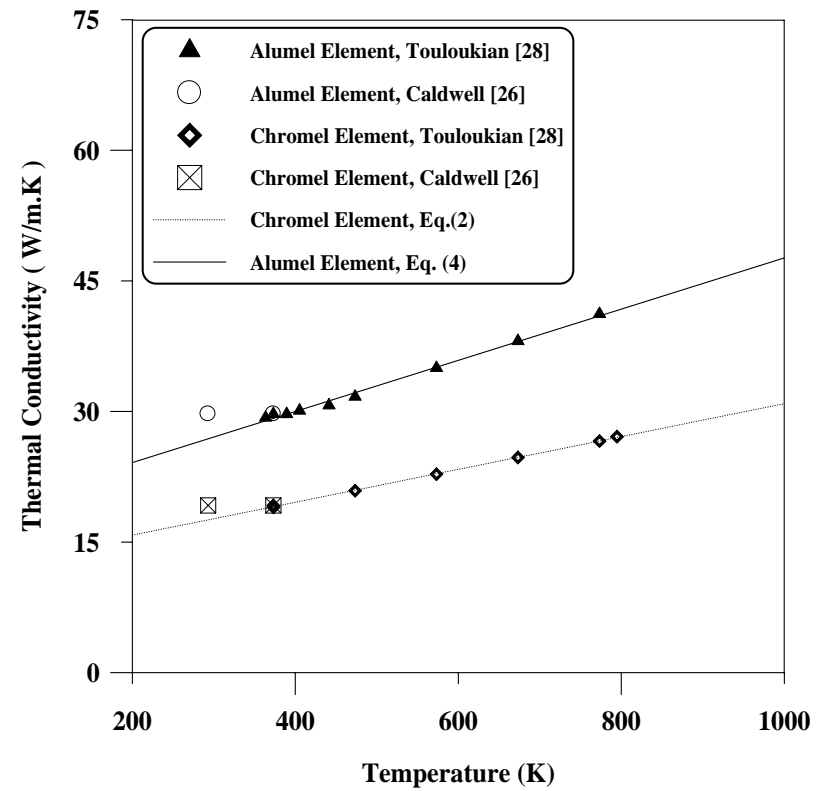

Fig. (3). The thermal conductivity variation with the temperature for temperature sensor elements.

\section{EXPERIMENTAL CALIBRATION FACILITY}

The dynamic calibrations of the fabricated temperature sensors were performed in UNITEN shock tube facility to determine its response time and to confirm its capability for measuring the transient surface temperature and consequently making the transient heat flux. A full description of this facility is comprehensively reported in [18]. A brief description of the shock tube setup and its instrumentation is given below.

The layout of UNITEN shock tube facility is illustrated in Fig. (4). The facility consists of driver section; flange, wherein the diaphragm is placed; driven section; connection piece; working section (test section); end cap wall. The driver and driven sections are made of stainless steel, 304L grade, and designed to withstand $20 \mathrm{MPa}$ pressure. They are $2.5 \mathrm{~m}$ and $4.25 \mathrm{~m}$ in long respectively with $0.09 \mathrm{~m}$ outside diameter and $0.05 \mathrm{~m}$ inside diameter for each. The diaphragm, a thin instantaneously removable diaphragm aluminum sheet with $0.2 \mathrm{~mm}$ thick, is placed in the flange between the driver and driven sections till the compression process is initiated. These diaphragms will be burst if subjected to a pressure difference of $2 \pm 0.07 \mathrm{MPa}$.

At the downstream end of the driven section, a $0.5 \mathrm{~m}$ length, $0.05 \mathrm{~m}$ inner diameter and $0.09 \mathrm{~m}$ outer diameter stainless steel tube is called 'test section' or 'working section'. It is interconnected with the driven section using a connection piece, with $0.15 \mathrm{~m}$ length and $0.13 \mathrm{~m}$ diameter. This test section is used to calibrate the measuring instrumentation including the constructed temperature sensor. The successful temperature sensors with different forms of scratched junctions were installed and glued into bushes at different axial locations along the test section as shown in Fig. (5), which were themselves located on a recessed shoulder and locked in place with a nut. The test section temperature sensors were aligned with the inner surface of the driven section to within approximately $0.1 \mathrm{~mm}$, so that their sensing point approximately flash mounted with the inner surface of the test section.

The driver and driven sections of the shock tube are equipped with a pressure gauge with a maximum pressure range up to $16 \mathrm{MPa}$ with an accuracy of $\pm 70 \mathrm{kPa}$, to monitor the filled pressure inside the driver or driven sections. A vacuum pressure gauge with an accuracy of $0.2 \pm 0.07 \mathrm{MPa}$, is also installed in the driver and driver sections together with its vacuum pump to regulate the gas inside the driver or driven section into different pressure values ranging from 0.1 $\mathrm{MPa}$ to $0.025 \pm 0.07 \mathrm{MPa}$. The vacuum pump was used when the gas inside the driver or driven section is not air (eg. helium or $\mathrm{CO}_{2}$ ) then the driver or driven section should be evacuated and refilled with the required gas. There is also a piezoresistive static pressure transducer with a maximum pressure of $25 \mathrm{MPa}$ with accuracy of $\pm 0.3 \% \mathrm{kPa}$. It is located at the end of the driver section and near the diaphragm position (flange) to monitor the exact diaphragm burst pressure history when the shock wave is propagating throughout the tube.

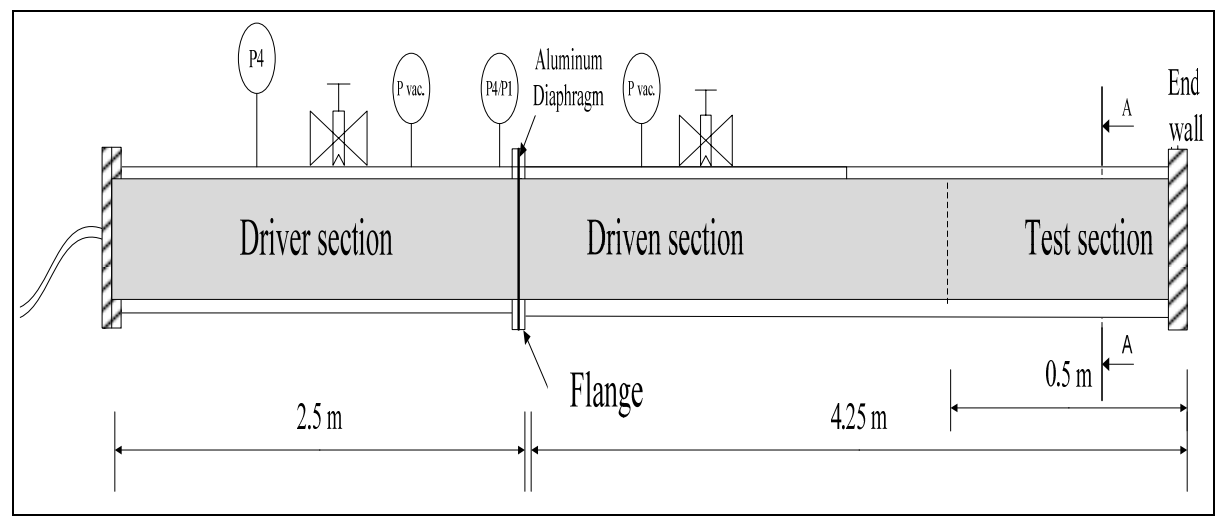

Fig. (4). UNITEN shock tube facility configuration. 


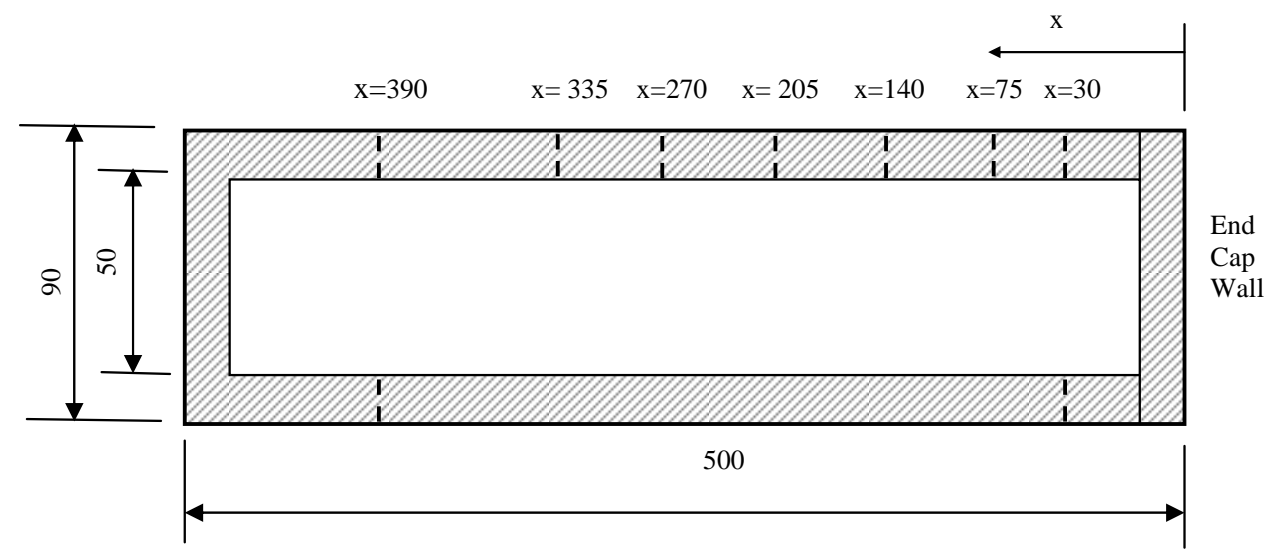

Fig. (5). Shock tube test section showing the locations of the measuring instrumentation, all dimensions are in $\mathrm{mm}$.

In this work, a test section with its end cap wall was designed and manufactured with different axial and radial distances. This test section contains nine holes drilled with 20 $\mathrm{mm}$ diameter and $20 \mathrm{~mm}$ deep. Seven of them were located in the upper part of the test section to capture and gather the transient surface temperature rise within the test section's wall using the fabricated temperature sensors. Another two holes were located in the lower part of the section, which were used for capturing and gathering the pressure history data from the two piezoelectric pressure transducers (PCB Piezotronics Inc., Model 111A24) with $70 \mathrm{MPa}$ maximum pressure with an accuracy of $\pm 0.2 \%$, which were flushmounted with the tube inner surface precisely with $360 \mathrm{~mm}$ apart as shown in Fig. (5). The pressure transducers were also used to measure the shock wave speed and to determine the precise time of the shock wave passed over the temperature sensor.

\section{THERMAL PRODUCT ESTIMATION METHOD}

In this work, the method of determining $\beta$ is performed by calibrating all in-house fabricated temperature sensors using shock tube facility under microsecond time scales. This is done to assess the performance of the fabricated temperature sensor using this transient facility and to demonstrate their capability to withstand the high enthalpy conditions. Therefore, the calibration equation, Eq.5, is employed as suggested by Jessen et al. [7]. The one-dimensional heat conduction theory serves as a basis for this equation. The theory depends on the $p c k$ values and the initial temperatures only and that it is independent of time.

$\frac{T_{T S}-T_{\infty}}{T_{R 5}-T_{\infty}}=\frac{\beta_{R 5}}{\beta_{R 5}+\beta_{T S}}$

Where $T_{R 5}$ an and $\beta_{R 5}$ are the temperature and the thermal product of the working fluid behind the reflected shock wave. $T_{T S}-T_{\infty}$ is the surface temperature rise measured by the fabricated temperature sensor and $\beta_{T S}$ is the thermal product for a particular temperature sensor which can be determined from Eq.5.

In this work, the temperature sensors were flush mounted in the downstream of the driven tube surface (test section) as well as in the end cap wall surface. Thus, when the shock wave reflects off from the end of wall of the shock tube, the working fluid experiences a step change in temperature (assuming idealized one dimensional gas dynamic and heat transfer processes) which its magnitude is ideally given by Eq.5. This equation was used to evaluate the value of $\beta$ for each temperature sensor under consideration with sufficient precision, departing from the recorded surface temperature and the temperature step in the working fluid during the shock reflection process at the end wall of the test section tube.

The working fluid temperature change $T_{R 5}-T_{\infty}$ was evaluated from the incident shock wave speed $(u)$ using a calorically imperfect, ideal gas analysis. The density $\left(P_{5}\right)$, pressure $\left(P_{5}\right)$ and the enthalpy $\left(h_{5}\right)$ of the working fluid behind the reflected shock wave were also calculated from the ideal gas equations as given by Anderson [29] and Zurcow [30]. The thermal conductivity of the working fluid was estimated using Sutherland's law given by White [31]:

$\frac{\kappa}{\kappa_{o}}=\left(\frac{T_{R 5}}{T_{o}}\right)^{\frac{3}{2}} \frac{T_{o}+S}{T_{R \mathbf{s}}+S}$

Where $K_{o}$ is the thermal conductivity of the working fluid at reference condition, $T_{o}$ is the temperature of the working fluid at reference condition, $S$ is the Sunderland constant. The constant pressure specific heat of the ideal gas was calculated using the following equation given by Vargaftik et al. [32]:

$c_{p}=\boldsymbol{R}\left(\sum_{j=0}^{6} \alpha_{j} \theta^{j}+\sum_{j=1}^{6} \beta_{j} \theta^{-j}\right)$

Where: $\alpha$ and $\beta$ are constants, $\theta=\frac{T_{R 5}}{100}, \boldsymbol{R}$ is the gas constant and $T_{R 5}$ is the temperature behind the reflected shock wave.

\section{RESULTS AND DISCUSSION}

A total of 80 test runs were carried out using 16 fabricated temperature sensors constructed using different scratch techniques (its details is presented in Table 1, Appendix A). The experiments were conducted using helium- $\mathrm{CO}_{2}$ combination in the shock tube facility with different diaphragm pressure ratio $\left(P_{4} / P_{I}\right)$ ranging from 10-200. This is to demonstrate the temperature sensor performance and to measure 


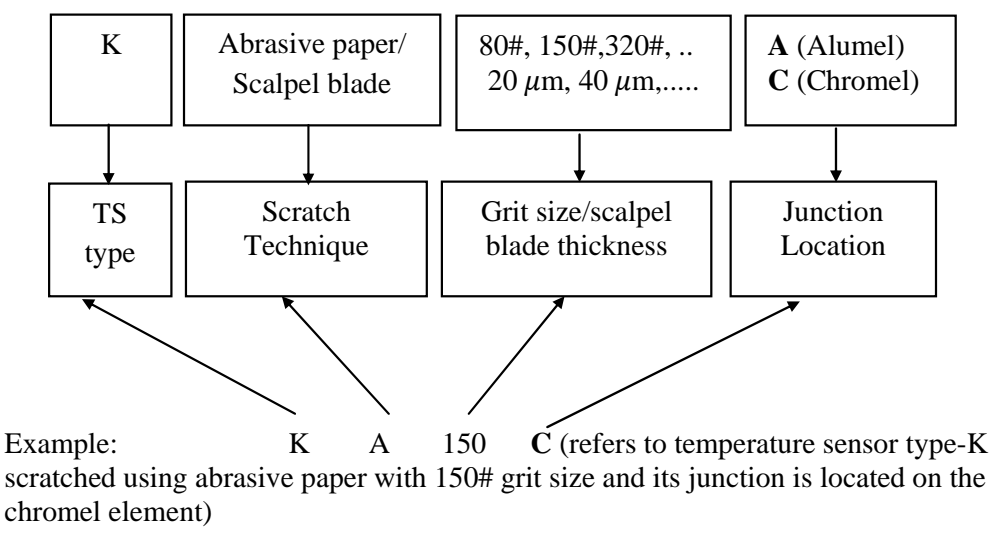

Fig. (6). Designation of the fabricated temperature sensor.

the transient surface temperature in order to eventually deduce the heat transfer rate. Fig. (6) shows the designation of the fabricated temperature sensor used in this work. Some of the temperature sensors were fabricated repeatedly to assess the sensors for possible damage and its repeatability after many experiments. Other temperature sensors were refurbished during the experiments due to the erosion of its sensing surface (Table 1, Appendix A). The value of thermal product for each individual temperature sensor is predicted by measuring the true surface temperature. The temperature sensor response and rise time are also investigated.

The accurate measurement of the driver pressure $\left(P_{4}\right)$ is actually not necessary because the input pressure pulse can be obtained from accurate measurements of shock wave speed $(u)$ or from Mach number $\left(M_{s}\right)$, driven section pressure $\left(P_{1}\right)$ and temperature $\left(T_{l}\right)$. The test run was initiated when the aluminum diaphragm separating the driver and driven sections was burst. The test conditions were based on measuring of the initial shock tube fill pressure and temperature. The remaining test section parameters, including the incident shock speed prior to reflection, reflected shock wave speed, the temperature and pressure of the reflected shock wave, were directly determined from the measured quantities using the ideal gas dynamics equations given by Anderson [29] and Zurcow [30]. The ambient shock tube temperature, before test run, was taken as a nominal $295 \mathrm{~K}$.

\section{A) Surface Temperature Rise}

Example of the output temperature sensor produced by the current temperature sensor formed with different scratch techniques is shown in Fig. (7) for selected test runs. This figure obviously shows that there is a small change in the surface temperature rise. This is due to the difference between the thermal product of the working fluid $\left(\mathrm{CO}_{2}\right.$ in this case) compared with that of the temperature sensor, even though there is a large change in $\mathrm{CO}_{2}$ temperature due to shock wave compression. Furthermore, there is ideally no movement of the $\mathrm{CO}_{2}$ in contact with the temperature sensor immediately following the shock reflection. Thus, the $\mathrm{CO}_{2}$ remains stationary for only a short period of time following shock reflection due to the boundary layer jetting effect which affects the $\mathrm{CO}_{2}$ at the end of the shock tube.

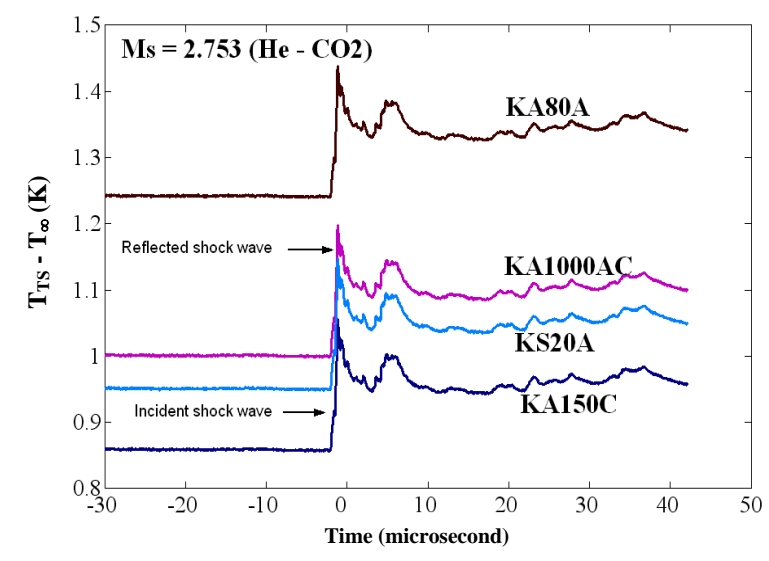

Fig. (7). The surface temperature rise history measured by different temperature sensors at $\mathrm{M}_{\mathrm{s}}=2.753$.

Fig. (7) also shows that there are two main peaks in the surface temperature rise history. The first peak reveals to the propagation of the incident shock wave which compresses and heats the $\mathrm{CO}_{2}$ to a higher temperature as indicated on the figure. The second peak refers to the reflected shock wave propagation which is again compressed and heated the $\mathrm{CO}_{2}$ to a higher temperature. Then, the surface temperature starts eventually to be uniform after the strength of the incident shock and reflected shock waves become weak. For example, the surface temperature for temperature sensor KA150C was increased in the first peak to $0.92 \mathrm{~K}$ whereas it was increased to $1.02 \mathrm{~K}$ in the second peak. Furthermore, Fig. (7) illustrates that the surface temperature rise value slightly differs for each temperature sensor. This depends on the way of forming the junction, the junction location on the positive/negative element and its vicinity to the insulation layer. This will be further investigated and interpreted in the next sections.

The operating experimental conditions are presented in Table 2 (Appendix A) and the experimental results are tabulated in Table $\mathbf{3}$ (Appendix A) using shock tube facility for helium- $\mathrm{CO}_{2}$ combination. This is to predict the appropriate thermal product for each particular temperature sensor that could consequently be used for accurate transient heat flux 
determination. Six test runs from low enthalpy to high enthalpy were carried out to assess the temperature sensor performance. It was observed from the testing in shock tube facility that there was a noisy response from the following sensors KA400A, KA1200AC, KS20C and KS40C as they are short circuited. This is probably happened due to the imperfect contact between the sensor elements and also due to the lack of the electrical insulation amount between those two elements. Thus, their results are shielded as they need to be re-fabricated.

\section{B) Thermal Product Values}

The thermal product values produced from the experimental dynamic calibration results are plotted and depicted in Figs. (8 and 9). It can be seen that the thermal product $\left(\beta_{T S}\right)$ for each particular temperature sensor is a function of the calibration conditions (temperature of the working fluid and the enthalpy). Thus, it is revealed that the variability (standard deviation of the mean values) of the fabricated temperature sensor differs from one to another as it depends on the scratch technique used and on the junction location. It is also noticed from helium- $\mathrm{CO}_{2}$ experiments that there is variability in the fabricated temperature sensors. However, the scratched temperature sensors using abrasive paper and scalpel blade show close variability except KA600AC and KS20A whose variability are $10.02 \%$ and $10.26 \%$ respectively. The variability for KA80A is $4.54 \%$, for KA $150 \mathrm{C}$ is $2.31 \%$, for $\mathrm{KA} 320 \mathrm{AC}$ is $9.61 \%$, for $\mathrm{KA} 1000 \mathrm{AC}$ is $8.92 \%$, for $\mathrm{KA} 1500 \mathrm{AC}$ is $8.39 \%$, for $\mathrm{KS} 40 \mathrm{C}$ is $4.19 \%$, for $\mathrm{KS} 60 \mathrm{~A}$ is $1.02 \%$ and for $\mathrm{KS} 60 \mathrm{C}$ is $1.41 \%$.

In the analysis of each test run, the recorded step surface temperatures using helium- $\mathrm{CO}_{2}$ combination were then combined with the thermal product for $\mathrm{CO}_{2}\left(\beta_{R 5}\right)$ to deduce the thermal product for the fabricated temperature sensor. For the experiments where the sensor junction was formed by scalpel blade scratch technique, the thermal product values for each run are plotted in Fig. (8). It was observed that when the junction was formed on the alumel element, the mean values of the thermal product for the test runs produced from KS20A and KS60A varied between 11009.26 and 11190.01 $\mathrm{J} / \mathrm{m}^{2} \mathrm{~K} \mathrm{~s}^{1 / 2}$. These thermal product values correspond closely to that of alumel identified from the correlation equations developed earlier. However, when the junction was formed on the chromel element, the mean values of the thermal product for the test runs produced from KS40C and KS60C varied between 9264.02 and $9270.11 \mathrm{~J} / \mathrm{m}^{2} \mathrm{~K} \mathrm{~s}^{1 / 2}$. Both of these values are closer to each other and are higher than the correlated value for chromel identified from the correlation equations. It is worth mentioning that the derivation of the thermal product from the measured data is slightly sensitive to the temperature difference $\left(T_{T S}-T_{\infty}\right)$ than it is to the thermal product for $\mathrm{CO}_{2}$. Thus, the uncertainty in $\left(T_{T S}-T_{\infty}\right)$ is estimated to be $\pm 1.2 \%$ and the estimated uncertainty in the sensor thermal product is approximately $\pm 2.8 \%$ with the strongest contribution from the uncertainty in the thermal product of $\mathrm{CO}_{2}$. This level of uncertainty may consequently contribute to the differences in the measured and correlated chromel values. Furthermore, another factor need to be considered which is that the temperature sensor is actually composed of three different materials that contribute to the thermal product value as has been approved by the same authors in [21]. Furthermore, it seems that some of the junctions are located into the area close to the alumel element and other are located in the proximity of the electrical insulation area. Therefore, the difference between the thermal product value for the junctions formed using scalpel blade scratch technique onto alumel and chromel elements remains consistent for all of the scalpel scratched junctions tested. These results may suggest that it could not be necessary to calibrate each temperature sensor to determine its thermal product value. Therefore, based on the present results, the thermal product for sensor whose junction formed on the alumel element can be taken as $11099.64 \mathrm{~J} / \mathrm{m}^{2} \mathrm{~K} \mathrm{~s}^{1 / 2}$ with $95 \%$ confidence limits of $\pm 4.18 \%$. The thermal product can be taken as 9267.06 $\mathrm{J} / \mathrm{m}^{2} \mathrm{~K} \mathrm{~s}^{1 / 2}$ with $95 \%$ confidence limits of $\pm 1.82 \%$ for sensor whose junction formed on the chromel element.

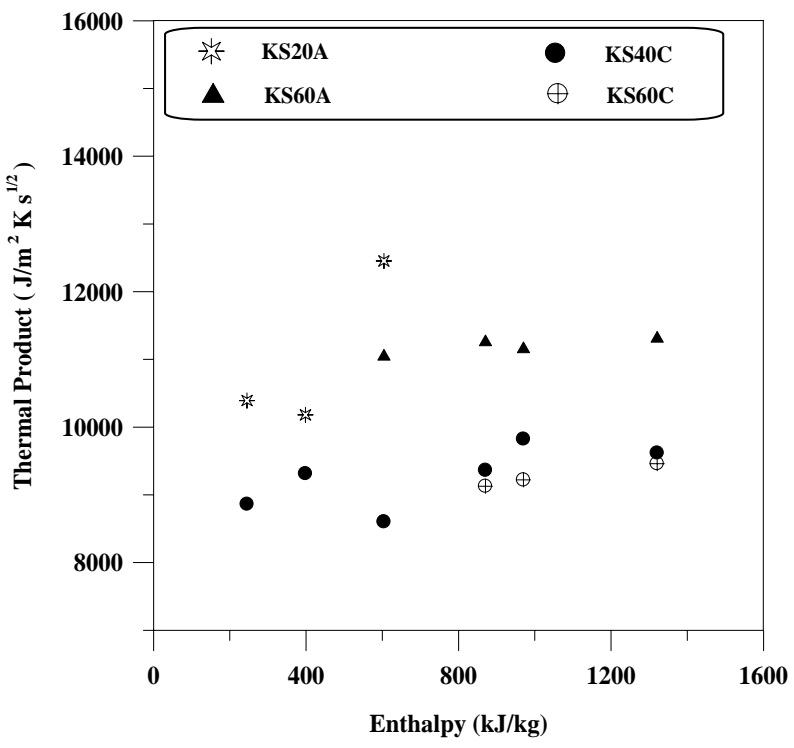

Fig. (8). Thermal product variation versus enthalpy for different temperature sensors scratched using scalpel blade.

The situation is somewhat different when the temperature sensor junctions are created using abrasive paper scratch technique. For sensors scratched using coarser grit size of abrasive paper (e.g. KA80A) from chromel element onto the alumel element. In this case, multiple junctions were created by carefully drawing a small area of grit size of abrasive paper from chromel element onto the alumel element and all localized junctions were created on the alumel element. Thus, the average value of the thermal product is 10561.56 $\mathrm{J} / \mathrm{m}^{2} \mathrm{~K} \mathrm{~s}^{1 / 2}$ which is obviously lower than the value of thermal product of the sensor scratched using scalpel blade (i.e. KS20A and KS60A). When the sensor junction was formed using much finer grit size scratch such as KA600AC, KA1000AC and KA1500AC, the effective locations of the sensor junctions are much closer to the insulation layer than when the scalpel blade was used to create the junctions. In this case a relatively large area of abrasive paper is drawn across the entire face of the temperature sensor; therefore, the junctions are likely to be created on both alumel and chromel elements. The number of junctions on each element of the temperature sensor may not be equal, so it is possible that the thermal product of one of the element materials may dominate. In addition, the thermophysical properties of the insulation layer have a stronger influence on the effective 
values of the thermal product when finer junctions are created with abrasive papers. Thus, the mean values of thermal product of the above three sensors can be taken as 11289.02 $\mathrm{J} / \mathrm{m}^{2} \mathrm{~K} \mathrm{~s}^{1 / 2}$ with $95 \%$ confidence limits of $\pm 6.32 \%$ even there is small variations in their values as shown in Fig. (9). The observed variations in the thermal product values for temperature sensor junctions is due to: (i) the difference of the thermophysical properties of the sensor two elements materials coupled with the uncertain weighting for each; and (ii) the differences in the proximity of the junction to the insulation layer due to construction variability.

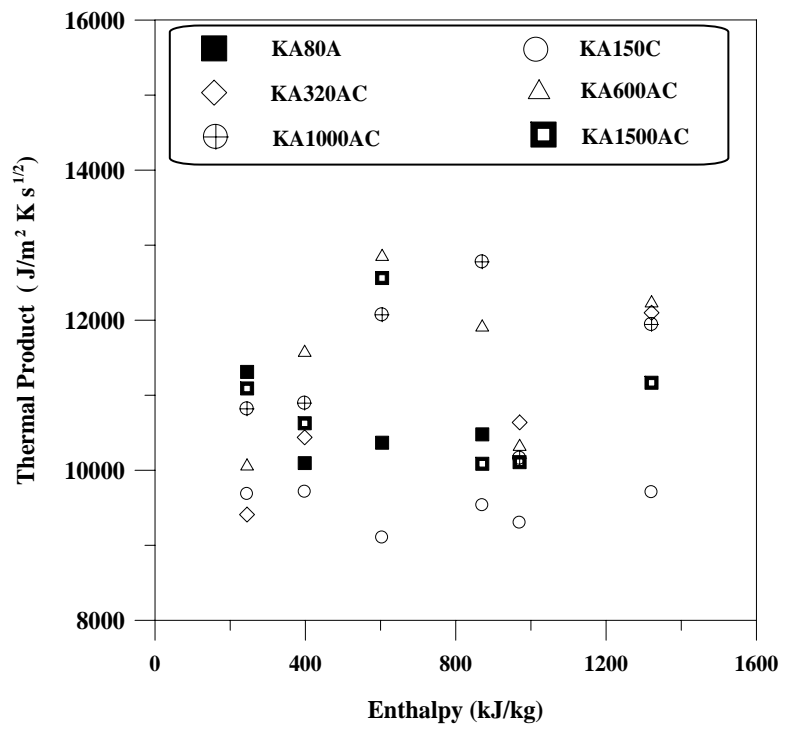

Fig. (9). Thermal product variation versus enthalpy for different temperature sensors scratched using abrasive paper.

\section{C) Sensors Rise Time}

Recalling the surface temperature rise behavior illustrated in Fig. (7) for selected temperature sensor scratched using different techniques. The results have indicated that a small change of the temperature level has occurred by $5 \mu \mathrm{s}$ after shock reflection, so a more conservative approach was adopted in the analysis of the present results. In order to identify the step in the surface temperature for each result, the recorded signal from a particular temperature sensor was averaged over the period from 0 to $2 \mu$ s after shock reflection. Examples of the signals obtained during the time period to $2 \mu$ s from shock reflection are depicted in Figs. (10 and 11) for selected temperature sensors to identify the rise time of the fabricated temperature sensor.

It was noticed that the rise time for temperature sensor with junctions formed using abrasive paper was consistently less than $0.3 \mu \mathrm{s}$ as illustrated in Fig. (10). This figure presents the rise time for temperature sensor scratched using abrasive paper from coarser grit size with 150\#. However, some of the temperature sensor exhibited a rise time a bit greater than $0.3 \mu$ s such as KA320AC scratched with $320 \#$ grit size of abrasive paper due to the poorness signal-to-noise ratio. Thus, the apparent value of thermal product for this temperature sensor is much larger, and there is greater variation in thermal product values for KA320AC (variability
9.61\%) relative to that for KA $80 \mathrm{~A}$ (variability $4.54 \%$ ). The shock tube experiments have revealed that some of the fabricated temperature sensors using scalpel blades produced rise time less than $0.3 \mu$ s as presented in Fig. (11). However, others temperature sensors produced rise time approximately $0.3 \mu$ s such as KS20A due to the poorness signal-to-noise ratio produced from this temperature sensor. Thus, the apparent value of thermal product is much larger, and there is greater variation in thermal product values for KS20A (variability $10.26 \%$ ) relative to that for KS60A (variability $1.02 \%$ ). Furthermore, this is happened by the fact that those temperature sensors were created by hand and there was probably considerable variability in the effective depth of the junction which has a direct impact on the rise time of the temperature sensor.

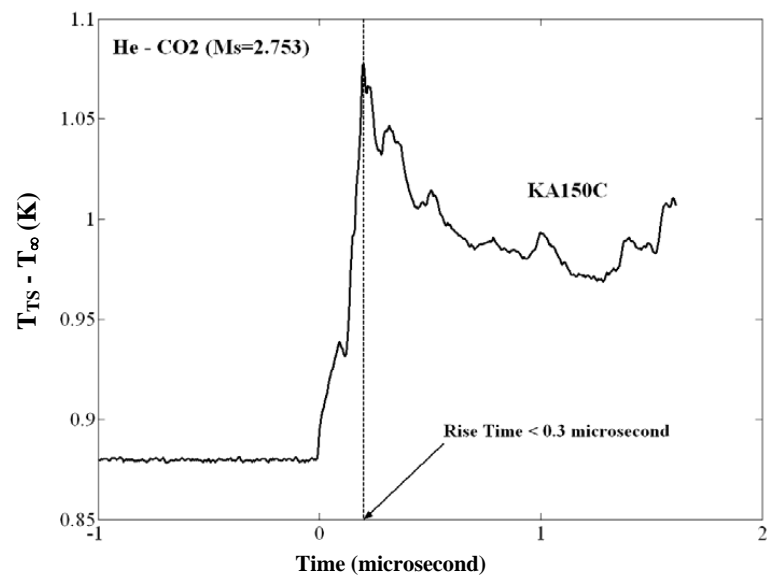

Fig. (10). The rise time for temperature sensor scratched using abrasive paper.

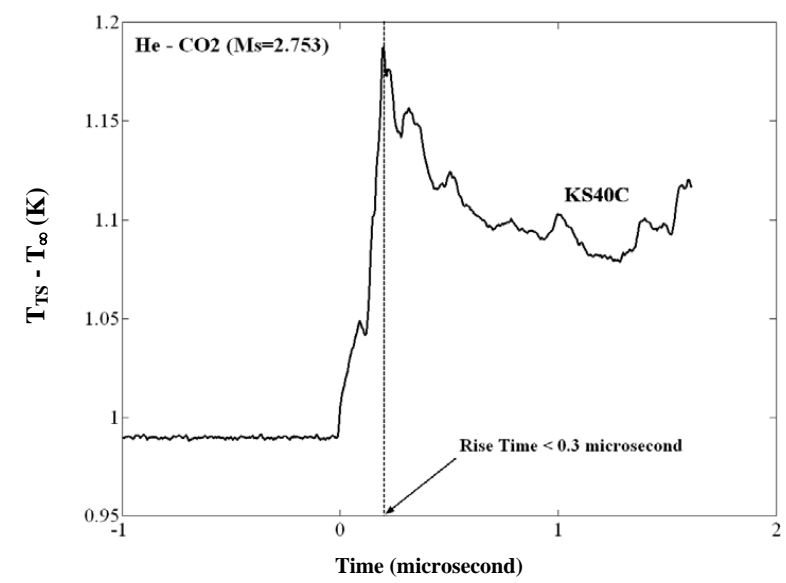

Fig. (11). The rise time for temperature sensor scratched using scalpel blade.

\section{D) Numerical Determination of Surface Heat Flux History}

In short duration flow (hypersonic facilities) usually the surface temperatures of the models do not reach the high levels that occur with the real vehicle during flight, so that the temperature itself is of a minor interest. The heat flux is a more meaningful quantity which can easily be simulated and remains constant during the test time in shock tube facility. 
In order to relate the measured surface temperature to the actual heat transfer rate, it is useful to use the following assumption: (i) the sensing surface of the temperature sensor has negligible effects on the surface thermal behavior; (ii) the thermal penetration depth is less than the thickness of the substrate; (iii) the temperature sensor may be considered as a uniform semi-infinite solid. The technique used to derive the heat flux involves the measurement of the surface temperature history and the subsequent calculation of the surface heat flux history by means of unsteady one-dimensional heat conduction theory. The following expression can be solved for the surface heat flux determination in terms of the surface temperature [33]:

$q(t)=-\kappa \frac{\partial T(0, t)}{\partial x}=\frac{\beta}{\sqrt{\pi}} \int_{-0}^{t} \frac{d T_{s}}{d t} \frac{1}{\sqrt{t-\tau}} d \tau$

From the above equation it is apparent that in order to perform heat flux calculations, it is necessary to determine the thermal product values of the temperature sensor. These values were determined from dynamic calibration of the fabricated temperature sensor as presented in the previous sections. If the heat flux is not constant, the numerical technique must be used in the calculation of the heat transfer rate because of the temperature derivative, the integral in Eq. 8 is not suitable for numerical evaluation. Therefore, to reduce the error introduced by the uncertainty in the integral term in Eq.8. It is more customary to use the following equivalent expression for the evaluation of the surface heat flux.

$q_{s}(t)=\frac{\beta}{\sqrt{\pi}}\left(\frac{T_{s}(t)-T_{i}}{\sqrt{t}}+\frac{\mathbf{1}}{2} \int_{0}^{t} \frac{T_{s}(t)-T_{s}(\tau)}{(t-\tau)^{0.5}} d \tau\right)$

Where $\beta$ is the thermal product of the fabricated temperature sensor which describes the influence of the thermophysical properties of the temperature sensor materials on the unsteady heat transfer. The numerical algorithm used to solve Eq.9 was done by developing a MATLAB ${ }^{\circledR}$ routine to obtain the transient heat flux history from the measured surface temperatures history according to Cook and Flederman $[34,35]$. A sample of the transient heat flux history produced from the surface temperature history, measured using one of the fabricated temperature sensor KA600AC whose junction was formed using abrasive paper of $600 \#$ grit size is shown in Fig. (12).

A large spike in the deduced heat flux history can be seen from this figure for times in the range of 0.3 to $0.6 \mu \mathrm{s}$. This spike is attributed to shock wave transient that are known to occur during the starting of the test run in shock tube facility. The shape of the heat flux reflects the form of the surface temperature rise. It can also be seen that the first peak in the surface heat flux was obviously around $0.78 \mathrm{MW} / \mathrm{m}^{2}$ whereas the second peak was around $3.2 \mathrm{MW} / \mathrm{m}^{2}$.

\section{RESULTS REPEATABILITY AND UNCERTAINTY ANALYSIS}

The repeatability of the experimental results was performed into two categories; (i) repeating a particular experiment under the same operating conditions; (ii) repeating a particular temperature sensor design and fabrication using the same materials and using same scratch technique such as $\mathrm{KA} 80 \mathrm{~A} / \mathrm{R}^{*}, \mathrm{KA} 150 \mathrm{C} / \mathrm{R}^{*}$ (Table 1, Appendix A) to check their repeated response. Furthermore, it was demonstrated that the sensitivity of the temperature sensor depends on the thermophysical properties of its elements. All temperature sensor used in this work were manufactured from the same piece of raw materials. The repeatability of the measurement for each type of temperature sensor was within $\pm 5 \%$. In addition, the repeatability of the shock tube calibration technique was also assessed using data from test runs 1 to 6 (Table 2, Appendix A) which were essentially repeated experiments with the same configuration. Considering the data for $\mathrm{KA} 80 \mathrm{~A} / \mathrm{R}^{*}$, these runs produced a mean value of $\beta_{a l}=$ $11748.63 \mathrm{~J} / \mathrm{m}^{2} \mathrm{~K} \mathrm{~s}^{1 / 2}$ with a standard deviation of $5.02 \%$. This level of variability is significantly higher than the uncertainty estimates which indicate that the strongest contributions to the calculated values of $\left(T_{T S}-T_{\infty}\right)$ are from the measured shock speed (uncertainty of $\pm 0.5 \%$ ) and the thermal conductivity of $\mathrm{CO}_{2}$ (uncertainty of $\pm 2 \%$ ), yielding a

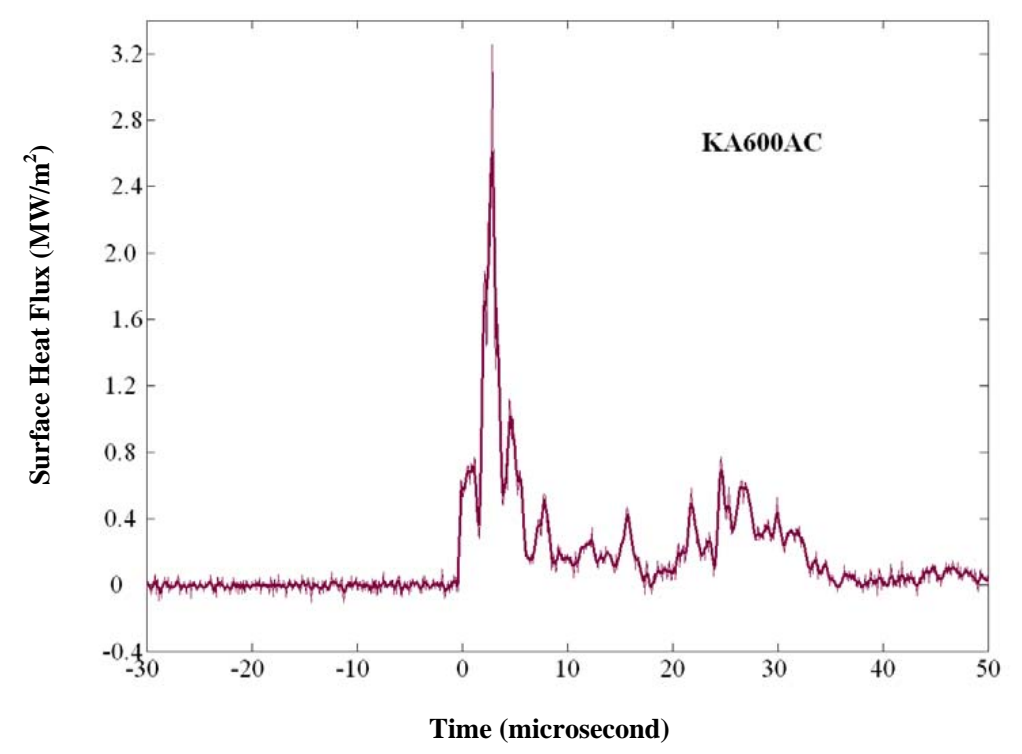

Fig. (12). The surface heat flux history produced from the temperature measured by temperature sensor KA600AC. 
total uncertainty of $\pm 2.5 \%$. The difference between the duplicated experimental test runs was within $\pm 2 \%$.

Therefore, the overall uncertainty were estimated for all test runs and for all values of driver pressure $\left(P_{4}\right)$, driven pressure $\left(P_{1}\right)$, shock wave speed $(u)$, reflected wave speed $\left(U_{R}\right)$ and surface temperature $\left(T_{T S}-T_{\infty}\right)$ using the method outlined in $[36,37]$. It was found, from the experiments conducted in this work, that the overall uncertainty for the static and dynamic pressure measurements arises from calibration uncertainty is around $\pm 2 \%$, scatter due to run to run variations is about $\pm 2 \%$, amplifier and sampling accuracy (both $\pm 1 \%$ ), and errors in the base line pressure $( \pm 2 \%$ for static pressure, negligible for dynamic pressure), giving an overall uncertainties of approximately $\pm 5 \%$ for static pressure and $\pm 3 \%$ for dynamic pressure. The uncertainty in the heat flux arises from the uncertainty in thermophysical properties of the temperature sensor elements $( \pm 4 \%)$, in the thermoresistive properties of the elements $( \pm 2 \%)$, scatter due to run to run variations $( \pm 2 \%)$, and amplifier and sampling accuracy (both $\pm 1 \%$ ), giving an overall uncertainty of approximately $\pm 5 \%$.

It can be inferred that the temperature sensor performance was obtained repeatedly and without difficulty after initial development of the sensor [18]. Noise levels in the measured surface temperature were acceptably very low due to the feasible design of the amplifier. The temperature sensor set was used for a minimum of 80 test runs of the shock tube facility. At the end of the test runs sequence, no gauge failures or performance degradation had been observed.

\section{CONCLUSIONS}

An experimental calibration technique using shock tube transient facility with different operating conditions was conducted to evaluate the thermal product value for temperature sensor with different scratched techniques. The performance, rise time and the surface heat flux produced from these sensors were also discussed in this paper. The conclusions worth noting in this work are further summarized in the following points:

- This paper has provided a useful and practical data for thermal product values for different scratched temperature sensors. These data are helpful to the experimentalists in the field and it can be used for accurate transient heat transfer rate.

- The temperature sensor performance is significantly influenced by the way of forming the surface junction which in turn affect the thermal product value. Thus, the effects of the thermophysical properties of different substrates on the temperature sensor thermal product have been examined. New correlation equations for evaluating the thermophysical properties of the temperature sensor have been derived.

- The practical implementation of calibrating the temperature sensors in shock tube facility has provided that there is a tendency for the thermal product of the temperature sensor to be different when it is formed using different scratch technique. It was inferred that the accurate thermal product value of a particular temperature sensor depends upon whether the junction was actually located on the positive or negative element or on both and on its proximity to the thin insulating layer between the two elements.

- The dynamic calibration results have shown that the thermal product of a particular temperature sensor depends on the Mach number, surface junction scratch technique, junction location as well as on the enthalpy conditions. It was also noticed based on the present results that the fabricated temperature sensor using scalpel blade technique with a particular blade size gives consistent thermal product values (to within $\pm 4.97 \%$ ). Thus, it does not require an individual calibration. However, a calibration for each temperature sensor whose junction created using abrasive paper with different grit sizes, is likely to be needed.

- It was demonstrated that there are significant differences between the thermal product for junctions formed on the chromel element and those formed on alumel element using scalpel blade technique. It was observed that the thermal product for alumel is larger than that of chromel in approximately $17.33 \%$.

- The rise time for temperature sensor whose junction created with abrasive paper was consistently less than $0.3 \mu \mathrm{s}$ for most of the fabricated temperature sensors. However, some of the temperature sensors scratched using scalpel blades have a rise time approximately $0.3 \mu \mathrm{s}$.

- When the heat flux was not constant, the numerical technique was used in the calculation of the heat transfer rate. The numerical algorithm used to solve the expression for the surface heat flux was done by developing a MATLAB routine to obtain the transient heat flux history from the measured surface temperatures history.

\section{APPENDIX A}

Table 1. Details of the Fabricated Temperature Sensors Using Abrasive Paper and Scalpel Blade Scratch Techniques

\begin{tabular}{|c|c|c|c|c|c|}
\hline $\begin{array}{l}\text { Temperature } \\
\text { Sensor No. }\end{array}$ & $\begin{array}{c}\text { Scratch } \\
\text { Technique }\end{array}$ & $\begin{array}{c}\text { Grit Size No./Scalpel } \\
\text { Blade Thickness }\end{array}$ & $\begin{array}{c}\text { The Way of Forming } \\
\text { the Junction }\end{array}$ & The Junction Location & $\begin{array}{l}\text { Insulation } \\
\text { Thickness }\end{array}$ \\
\hline KA80A & Abrasive paper & $80 \#$ & chromel to alumel & alumel (A) & $20 \mu \mathrm{m}$ \\
\hline $\mathrm{KA} 80 \mathrm{~A} / \mathrm{R}^{*}$ & Abrasive paper & $80 \#$ & chromel to alumel & alumel (A) & $18 \mu \mathrm{m}$ \\
\hline KA150C & Abrasive paper & $150 \#$ & alumel to chromel & chromel (C) & $16.4 \mu \mathrm{m}$ \\
\hline
\end{tabular}


(Table 1). Contd....

\begin{tabular}{|c|c|c|c|c|c|}
\hline $\begin{array}{l}\text { Temperature } \\
\text { Sensor No. }\end{array}$ & $\begin{array}{c}\text { Scratch } \\
\text { Technique }\end{array}$ & $\begin{array}{c}\text { Grit Size No./Scalpel } \\
\text { Blade Thickness }\end{array}$ & $\begin{array}{c}\text { The Way of Forming } \\
\text { the Junction }\end{array}$ & The Junction Location & $\begin{array}{l}\text { Insulation } \\
\text { Thickness }\end{array}$ \\
\hline $\mathrm{KA} 150 \mathrm{C} / \mathrm{R}^{*}$ & Abrasive paper & $150 \#$ & alumel to chromel & chromel (C) & $15 \mu \mathrm{m}$ \\
\hline $\mathrm{KA} 320 \mathrm{AC} / \mathrm{K}^{* *}$ & Abrasive paper & $320 \#$ & chromel to alumel & alumel and chromel (AC) & $15 \mu \mathrm{m}$ \\
\hline KA400A & Abrasive paper & $400 \#$ & chromel to alumel & alumel (A) & $17 \mu \mathrm{m}$ \\
\hline $\mathrm{KA} 600 \mathrm{AC} / \mathrm{K}^{* *}$ & Abrasive paper & $600 \#$ & chromel to alumel & alumel and chromel (AC) & $16 \mu \mathrm{m}$ \\
\hline $\mathrm{KA} 1000 \mathrm{AC} / \mathrm{K}^{* *}$ & Abrasive paper & 1000\# & chromel to alumel & alumel and chromel (AC) & $19.4 \mu \mathrm{m}$ \\
\hline KA1200AC & Abrasive paper & $1200 \#$ & chromel to alumel & alumel and chromel (AC) & $14 \mu \mathrm{m}$ \\
\hline $\mathrm{KA} 1500 \mathrm{AC} / \mathrm{K}^{* *}$ & Abrasive paper & $1500 \#$ & chromel to alumel & alumel and chromel (AC) & $18 \mu \mathrm{m}$ \\
\hline $\mathrm{KS} 20 \mathrm{~A}$ & scalpel blade & $20 \mu \mathrm{m}$ & chromel to alumel & alumel (A) & $18.8 \mu \mathrm{m}$ \\
\hline $\mathrm{KS} 20 \mathrm{C}$ & scalpel blade & $20 \mu \mathrm{m}$ & alumel to chromel & chromel (C) & $18 \mu \mathrm{m}$ \\
\hline KS40C & scalpel blade & $40 \mu \mathrm{m}$ & alumel to chromel & chromel (C) & $17.4 \mu \mathrm{m}$ \\
\hline $\mathrm{KS} 40 \mathrm{C}$ & scalpel blade & $40 \mu \mathrm{m}$ & alumel to chromel & chromel (C) & $16.6 \mu \mathrm{m}$ \\
\hline KS60A & scalpel blade & $60 \mu \mathrm{m}$ & chromel to alumel & alumel (A) & $16.9 \mu \mathrm{m}$ \\
\hline KS60C & scalpel blade & $60 \mu \mathrm{m}$ & alumel to chromel & chromel (C) & $18.8 \mu \mathrm{m}$ \\
\hline
\end{tabular}

A stands for Abrasive paper, A stands for Alumel element, $\mathbf{C}$ stands for Chromel element, AC stands for both Alumel and Chromel elements, K stands for temperature sensor type-K, $\mathrm{R}^{*}$ means the fabrication of a particular temperature sensor is repeated, ** means that this particular temperature sensor is re-refurbished, $\mathrm{S}$ stands for Scalpel blade.

Table 2. The Operating Experimental Conditions Used in Shock Tube Facility with Helium-CO $\mathrm{Combinations}_{2}$

\begin{tabular}{|c|c|c|c|c|}
\hline Run No. & Incident Mach Number $\left(\mathbf{M}_{\mathbf{s}}\right)$ & Enthalpy $(\mathbf{k J} / \mathbf{k g})$ & $\boldsymbol{T}_{R 5}(\mathbf{K})$ & $\boldsymbol{\beta}_{R 5}\left(\mathbf{J} / \mathbf{m}^{\mathbf{2}} \cdot \mathbf{K . s}{ }^{\mathbf{1} 2}\right)$ \\
\hline \hline 1 & 2.211 & 244.945282 & 703.7657 & 14.7029331 \\
\hline 2 & 2.753 & 398.384242 & 959.9344 & 19.952868 \\
\hline 3 & 3.371 & 604.063687 & 1317.035 & 26.564816 \\
\hline 4 & 4.057 & 870.781971 & 1796.055 & 28.819012 \\
\hline 5 & 4.289 & 970.154467 & 1977.857 & 39.456455 \\
\hline
\end{tabular}

Table 3. The Experimental Results from Shock Tube Facility with Helium-CO

\begin{tabular}{|c|c|c|c|c|}
\hline Run no. & Temperature Sensor No. & Scratch Technique & $\mathbf{T}_{\mathrm{TS}}-\mathbf{T}_{\infty}(\mathbf{K})$ & $\beta_{T S}\left(\mathbf{J} / \mathbf{m}^{2} . \mathbf{K} . \mathbf{S}^{1 / 2}\right)$ \\
\hline \multirow[t]{7}{*}{1} & KA80A & Abrasive paper $80 \#$ & 0.351 & 11309.493 \\
\hline & KA150C & Abrasive paper $150 \#$ & 0.41 & 9683.426 \\
\hline & KA320AC & Abrasive paper $320 \#$ & 0.422 & 9408.35 \\
\hline & KA600AC & Abrasive paper $600 \#$ & 0.395 & 10050.79 \\
\hline & KA1000AC & Abrasive paper $1000 \#$ & 0.367 & 10816.859 \\
\hline & KA1500AC & Abrasive paper $1500 \#$ & 0.358 & 11088.55 \\
\hline & KS20A & Scalpel blade $20 \mu \mathrm{m}$ & 0.382 & 10392.50 \\
\hline 冫 & KS40C & Scalpel blade $40 \mu \mathrm{m}$ & 0.448 & 8862.89 \\
\hline \multirow[t]{2}{*}{2} & KA80A & Abrasive paper $80 \#$ & 0.941 & 10094.43 \\
\hline & KA150C & Abrasive paper $150 \#$ & 0.978 & 9713.08 \\
\hline
\end{tabular}


Table 3. cont....

\begin{tabular}{|c|c|c|c|c|}
\hline Run no. & Temperature Sensor No. & Scratch Technique & $\mathbf{T}_{\mathrm{TS}}-\mathbf{T}_{\infty}(\mathbf{K})$ & $\beta_{T S}\left(\mathbf{J} / \mathbf{m}^{2} . \mathbf{K} . \mathbf{s}^{1 / 2}\right)$ \\
\hline & KA320AC & Abrasive paper $320 \#$ & 0.91 & 10437.818 \\
\hline & KA600AC & Abrasive paper $600 \#$ & 0.821 & 11567.777 \\
\hline & KA1000AC & Abrasive paper $1000 \#$ & 0.872 & 10892.06 \\
\hline & KA1500AC & Abrasive paper $1500 \#$ & 0.894 & 10624.37 \\
\hline & KS20A & Scalpel blade $20 \mu \mathrm{m}$ & 0.933 & 10180.86 \\
\hline & KS40C & Scalpel blade $40 \mu \mathrm{m}$ & 1.02 & 9313.71 \\
\hline \multirow[t]{8}{*}{3} & KA80A & Abrasive paper $80 \#$ & 1.971 & 10366.34 \\
\hline & KA150C & Abrasive paper $150 \#$ & 2.245 & 9103.485 \\
\hline & KA320AC & Abrasive paper $320 \#$ & 1.59 & 12845.444 \\
\hline & KA600AC & Abrasive paper $600 \#$ & 1.692 & 12072.28 \\
\hline & KA1000AC & Abrasive paper $1000 \#$ & 1.626 & 12561.49 \\
\hline & KA1500AC & Abrasive paper $1500 \#$ & 1.64 & 12454.43 \\
\hline & $\mathrm{KS} 20 \mathrm{~A}$ & Scalpel blade $20 \mu \mathrm{m}$ & 2.376 & 8602.68 \\
\hline & KS40C & Scalpel blade $40 \mu \mathrm{m}$ & 1.85 & 11042.95 \\
\hline \multirow[t]{8}{*}{4} & KA80A & Abrasive paper $80 \#$ & 3.816 & 10476.05 \\
\hline & KA150C & Abrasive paper $150 \#$ & 4.194 & 9534.26 \\
\hline & KA320AC & Abrasive paper $320 \#$ & 3.357 & 11904.8 \\
\hline & KA600AC & Abrasive paper $600 \#$ & 3.127 & 12778.48 \\
\hline & KA1000AC & Abrasive paper $1000 \#$ & 3.964 & 10085.91 \\
\hline & KA1500AC & Abrasive paper $1500 \#$ & 4.271 & 9362.85 \\
\hline & KS60A & Scalpel blade $60 \mu \mathrm{m}$ & 3.551 & 11255.87 \\
\hline & KS60C & Scalpel blade $60 \mu \mathrm{m}$ & 4.381 & 9128.425 \\
\hline \multirow[t]{8}{*}{5} & KA150C & Abrasive paper $150 \#$ & 5.231 & 9300.140 \\
\hline & KA320AC & Abrasive paper $320 \#$ & 4.572 & 10636.50 \\
\hline & KA600AC & Abrasive paper $600 \#$ & 4.716 & 10312.593 \\
\hline & KA1000AC & Abrasive paper $1000 \#$ & 4.787 & 10160.066 \\
\hline & KA1500AC & Abrasive paper $1500 \#$ & 4.813 & 10105.34 \\
\hline & $\mathrm{KS} 40 \mathrm{C}$ & Scalpel blade $40 \mu \mathrm{m}$ & 4.951 & 9824.48 \\
\hline & KS60A & Scalpel blade $60 \mu \mathrm{m}$ & 4.36 & 11152.277 \\
\hline & KS60C & Scalpel blade $60 \mu \mathrm{m}$ & 5.276 & 9221.063 \\
\hline \multirow[t]{8}{*}{6} & KA $150 \mathrm{C}$ & Abrasive paper $150 \#$ & 9.532 & 9706.94 \\
\hline & KA320AC & Abrasive paper $320 \#$ & 7.641 & 12099.46 \\
\hline & KA600AC & Abrasive paper $600 \#$ & 7.561 & 12227.055 \\
\hline & KA1000AC & Abrasive paper $1000 \#$ & 7.741 & 11943.660 \\
\hline & KA1500AC & Abrasive paper $1500 \#$ & 8.283 & 11164.71 \\
\hline & $\mathrm{KS} 40 \mathrm{C}$ & Scalpel blade $40 \mu \mathrm{m}$ & 9.621 & 9617.51 \\
\hline & KS60A & Scalpel blade $60 \mu \mathrm{m}$ & 8.177 & 11308.93 \\
\hline & KS60C & Scalpel blade $60 \mu \mathrm{m}$ & 9.781 & 9460.83 \\
\hline
\end{tabular}




\section{NOMENCLATURE}

$\begin{array}{llll}c & = & \text { Specific heat at constant pressure }(\mathrm{J} / \mathrm{kg} . \mathrm{K}) \\ M_{s} & = & \text { Shock Mach number } \\ q_{s} & = & \text { Surface heat flux }\left(\mathrm{W} / \mathrm{m}^{2}\right) \\ t & = & \text { Time from start of heating or cooling }(\mathrm{s}) \\ \kappa & = & \text { Thermal conductivity }(\mathrm{W} / \mathrm{m} . \mathrm{K}) \\ \kappa_{o} & = & \text { Thermal conductivity at reference condi- } \\ \boldsymbol{R} & = & \text { tions }(\mathrm{W} / \mathrm{m} . \mathrm{K}) \\ S & = & \text { Sunderland constant, Eq. }(6) \\ T & = & \text { Surface temperature measured by the sen- } \\ T_{i} & = & \text { Initial temperature }(\mathrm{K}) \\ T_{o} & = & \text { Temperature at reference conditions }(\mathrm{K}) \\ T_{s} & = & \text { Surface temperature }(\mathrm{K}) \\ T_{\infty} & = & \text { Ambient temperature }(\mathrm{K}) \\ u & = & \text { Shock wave speed }(\mathrm{m} / \mathrm{s}) \\ U_{R} & = & \text { Reflected shock wave speed }(\mathrm{m} / \mathrm{s}) \\ x & = & \text { Axial distance }(\mathrm{m})\end{array}$

\section{GREEK}

$\begin{array}{lll}\alpha & = & \text { Thermal diffusivity }(k / p c)\left(\mathrm{m}^{2} / \mathrm{s}\right) \\ \beta & = & \text { Thermal product }(\sqrt{\rho c \kappa})\left(\mathrm{J} / \mathrm{m}^{2} \mathrm{~K} \mathrm{~s}^{1 / 2}\right) \\ \sigma & = & \text { Standard deviation }(\%) \\ \rho & = & \text { Density }\left(\mathrm{kg} / \mathrm{m}^{3}\right) \\ \tau & = & \text { Dummy variable for integration wrt time }\end{array}$
(s)

\section{SUBSCRIPT}

$\begin{array}{lll}1 & = & \text { Conditions at driven section } \\ 4 & = & \text { Conditions at driver section } \\ 5 & = & \text { Conditions for reflected shock wave } \\ a l & = & \text { Alumel } \\ c r & = & \text { Chromel } \\ i & = & \text { Inlet } \\ R & = & \text { Reflected shock wave }\end{array}$

\section{REFERENCES}

[1] A.C. Alkidas, "Heat transfer characteristics of a spark Ignition Engine", J. Heat Transf ASME Trans., vol. 102, pp. 189-193, 1980.

[2] A.C Alkidas, R.M. Cole, "Transient heat flux measurements in a divided chamber diesel engine", J. Heat Transf. ASME Trans., vol. 107, pp. 439-444, 1985.

[3] A.C. Alkidas, P.V. Puzinauskas, and R.C. Peterson, "Combustion and heat transfer studies in a spark- ignited multi valve optical engine", SAE Trans. J. Engines, vol. 99, pp. 817-830, 1990.

[4] J.A. Gatowski, M.K. Smith, and A.C. Alkidas, "An experimental investigation of surface thermometry and heat flux", Exp. Therm. Fluid Sci., vol. 2, pp. 280-289, 1989.

[5] B. Lawton, "Effect of compression and expansion on instantaneous heat transfer in reciprocating internal combustion engines", Proc.
Instn. Mech. Eng. Part A J. Power Energy, vol. 201 no. (A3), pp. 175-186, 1987.

[6] D. J. Oude Nijeweme, J. B. W. Kok, C. R. Stone, and L. Wyszynski, "Unsteady in-cylinder heat transfer in a spark ignition engine: experiments and modeling", Proc. Instn Mech. Eng. Part D J. Automobile Eng., vol. 215, pp. 747-760, 2001.

[7] C. Jessen, M. Vetter, and H. Gronig, "Experimental studies in the Aachen hypersonic shock tunnel", Z. Flugwiss Weltraumforsch, vol. 17, pp. 73-81, 1993

[8] S.L. Gai, W.S. Joe, "Laminar heat transfer to blunt cones in highenthalpy flows", J. Thermophys. Heat Transf., vol. 6, pp. 433-438, 1992.

[9] S. R. Sanderson, B. Sturtevant, "Transient heat flux measurement using a surface thermocouple", Rev. Sci. Instrum., vol. 73, no.7, pp. 2781-2788, 2002.

[10] B. Lawton, G. Klingenberg, "Transient Temperature in Engineering and Science", Oxford University Press: Oxford, 1996.

[11] J.C. Chen, K.K. Hsu, "Heat transfer during liquid contact on superheated surfaces", J. Heat Transf. ASME Trans., vol. 117, pp. 693697, 1995.

[12] L. Lee, J.C. Chen, and R.A. Nelson, "Surface probe for measurement of liquid contact in film transition boiling on high temperature surfaces", Rev. Sci. Instrum., vol. 53, no. 9, pp. 1472-1476, 1982.

[13] L.Y.W. Lee, J.C. Chen, and R.A. Nelson, "Liquid-solid contact measurements using a surface thermocouple temperature probe in atmospheric pool boiling water", Int. Heat Mass Transf., vol. 28 , pp. 1415-1423, 1985.

[14] NANMAC, "Temperature Measurement Handbook", Framingham, MA: Nanmac Co. Publication, vol. VIII. 1997.

[15] D. Bendersky, "A special thermocouple for measuring transient temperatures", Mech. Eng., vol. 75, no. 2, pp. 117-121, 1953.

[16] A. Kovas, R.B. Mesler, "Making and testing small surface thermocouples for fast response", Rev. Sci. Instrum., vol. 35, no. 4, pp. $485-488,1964$

[17] L. Ongkiehong, J. Van Dujin, "Construction of a thermocouple for measuring surface temperatures", J. Sci. Instrum., vol. 37, pp. 221222, 1960.

[18] H. Mohammed, H. Salleh, M. Z. Yusoff, "Design and fabrication of coaxial surface junction thermocouples for transient heat transfer measurements", Int. J. Comm. Heat Mass Transf., vol. 35, no. 7, pp. 853-859, 2008.

[19] P. A. Kinzie, "Thermocouple Temperature Measurement", John Wiley \& Sons Inc., New York, 1973.

[20] K. Raznjevic, "Handbook of Thermodynamics Tables and Charts", Mc-Graw Hill: New York, 1976.

[21] H. Mohammed, H. Salleh, M. Z. Yusoff, "The transient response for different types of erodable surface thermocouples using finite element analysis", Int. J. Therm. Sci., vol. 11, no. 4, pp. 49-64, 2007.

[22] D. R. Buttsworth, "Assessment of effective thermal product of surface junction thermocouples on millisecond and microsecond time scales", Exp. Therm. Fluid Sci., vol. 25, no. 6, pp. 409-420, 2001.

[23] Y. Heichal, S. Chandra, and E. Bordatchev, "A fast response thin film thermocouple to measure rapid surface temperature changes", Exp. Therm. Fluid Sci., vol. 30, no. 2, pp. 153-159, 2005.

[24] T. Sprinks, "On the calibration of calorimeter heat transfer gauges", AIAA J., vol. 1, no. 2, pp. 464, 1963.

[25] P. R. A. Lyons, S. L. Gai, "A method for the accurate determination of the thermal product $\left(\mathrm{pck}^{1 / 2}\right)$ for thin film heat transfer or surface thermocouple gauges", J. Phys. E Sci. Instrum., vol. 21, pp. 445-448, 1998.

[26] F.R. Caldwell, Thermocouple Materials, "Applied Methods and instrument; temperature: Its measurement and control in science and industry", In: C.W. Herzfeld, Ed., Reinhold, New York, vol. 3, no. 2, pp. 81-134, 1962.

[27] Y.S. Touloukian, "Specific Heat Metallic Elements and Alloys, In: Y.S. Touloukian, Ed., Thermophysical Properties of Matter; temperature sensor RC Data series", IFI/Plenum press: New York, vol. 4, 1970.

[28] Y.S. Touloukian, "Thermal Conductivity Metallic Elements and Alloys, In: Y.S. Touloukian, Ed., Thermophysical Properties of Matter; Temperature Sensor RC Data Series", IFI/Plenum press: New York, vol. 1, 1970. 
[29] J.D. Anderson, "Modern Compressible Flow with Historical Perspective", $3^{\text {rd }}$ ed, Mc-Graw Hill: New York, 2004.

[30] M. J. Zurcow, J. D. Hoffman, Gas Dynamics, John Wiley \& Sons: Inc., New York, 1976.

[31] F.M. White, "Viscous Fluid Flow", $2^{\text {nd }}$ ed, Mc-Graw Hill: New York, 1991.

[32] N.B. Vargaftik, Y.K. Vinogradov, V.S. Yargin, "Handbook of Physical Properties of Liquids and Gases", $3^{\text {rd }}$ ed, Begell House: New York, 1996.

[33] J.V. Beck, B. St. Blackwell, C.R. Clair Jr., "Inverse Heat Conduction-II Posed Problems", John Wiley \& Sons: Inc., New York, 1985.
[34] W.J. Cook, E.J. Flederman, "Reduction of data from thin-film heat transfer gauges: A concise numerical technique", AIAA J., vol. 4, no. 3, pp. 561-562, 1966.

[35] W.J. Cook, "Determination of heat transfer rates from transient surface temperature measurements", AIAA J., vol. 8, no. 7, pp. 1366-1368, 1970.

[36] H.W. Coleman, W.G. Steele, "Engineering application of experimental uncertainty analysis", AIAA J., vol. 33, pp. 1888-1896, 1995.

[37] N.C. Baines, D.J. Mee, and M.L.G. Oldfield, "Uncertainty analysis in turbomachine and cascade testing", Int. J. Eng. Fluid Mech., vol. 4, no. 4, pp. 375-401, 1991.

(C) Mohammed et al.; Licensee Bentham Open.

This is an open access article licensed under the terms of the Creative Commons Attribution Non-Commercial License (http://creativecommons.org/licenses/by-nc/3.0/) which permits unrestricted, non-commercial use, distribution and reproduction in any medium, provided the work is properly cited. 